\title{
Sweet-potato washing revisited: 50th anniversary of the Primates article
}

\author{
Tetsuro Matsuzawa ${ }^{1,2}$
}

Published online: 14 September 2015

(C) Japan Monkey Centre and Springer Japan 2015

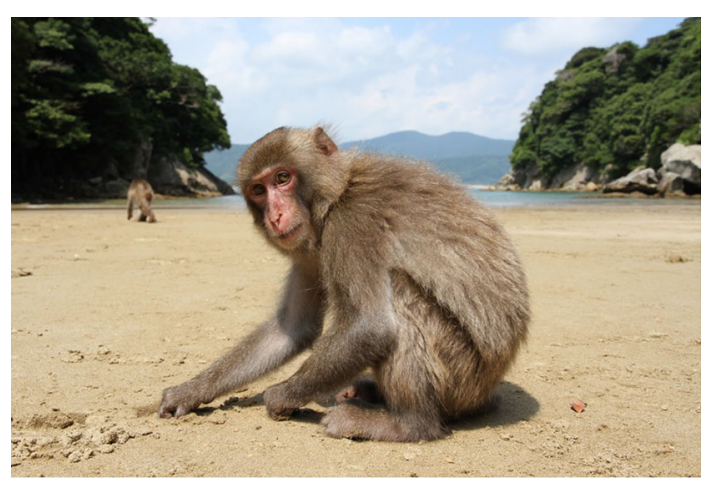

Koshima monkeys (Photo credit: Claire F I Watson)

I have just returned from Rome, Italy, where I attended the 6th Congress of the European Federation for Primatology. In total, my trip took 4 nights and 5 days with 1 night on the plane. This is representative of one of my typical journeys, travelling to give an invited talk at a conference in Europe or North America. At this particular conference, the sex ratio of attendees, males to females, was about 3:7 - so, a lot more female scholars than male.

I talked about my research on chimpanzees and took the opportunity to speak with both young scholars as well as catching up with old friends. Doing so brought home to me the long-term nature, and the advantages, of the study of nonhuman primates in Japan. There are no Italian monkeys, no French monkeys, no German monkeys, and no

Tetsuro Matsuzawa

matsuzawa.tetsuro.8w@kyoto-u.ac.jp

1 Primate Research Institute, Kyoto University, Inuyama, Japan

2 Japan Monkey Centre, Inuyama, Japan
British monkeys. Researchers based in these countries wishing to study wild populations must go either to Africa, Central or South America, India or South-East Asia for their fieldwork. Japan has indigenous monkeys: Japanese monkeys, or snow monkeys.

To primatologists, the most famous study involving Japanese monkeys concerns sweet-potato washing on Koshima Islet. The original paper was published in Primates in 1965. This year is the 50th anniversary of that particular publication. If you check Google Scholar, you will see that the paper has been cited 689 times.

Let me take this opportunity to introduce the sweetpotato washing of Japanese monkeys in a historical context. Koshima is a small islet of 32 ha, that is located about $200 \mathrm{~m}$ away from the mainland of Miyazaki prefecture. The highest point is $113 \mathrm{~m}$ above the sea level. There used to be a troop of monkeys but it split into two troops at this moment, about 100 individuals in total.

It was Tohichi Kanchi (1871-?) who lived in the mainland village and instigated a grass-roots effort to protect the monkeys living on Koshima Islet, well before the start of the Second World War. The Koshima monkeys were designated as a National monument in 1934 thanks to the effort of Mr. Kanchi. The Kyoto University scholar Kinji Imanishi (1902-1992) and his two undergraduate students, Junichro Itani (1926-2001) and Shunzo Kawamura (1924-2003) first reached Koshima on December the 3rd 1948. Imanishi initiated fieldwork on the Koshima monkeys, aided by his students.

Satsue Mito (1914-2012), daughter of Mr. Kanchi, helped the Kyoto University researchers. She was a teacher at a primary school on the mainland. Taking advantage of living so close to Koshima Islet, she often visited the monkeys and helped with the provisioning. The provisioning succeeded in August in 1952. One day in 
September 1953, Ms. Mito saw a female monkey, aged a year and a half, perform an unusual behavior. She washed a sweet potato in water. Mito had never before seen this behavior.

The news was brought to Kyoto University and caught hold of the researchers' attention. In the years following this observation, the scholars monitored the sweet-potato washing carefully. It was Kawamura who wrote the first paper on this topic. Then, based on a collective effort, Masao Kawai (1924-) wrote the first full paper in English (Kawai 1965), 12 years after the first sighting of the behavior by Ms. Mito.

In my opinion, a cultural behavior has at least three important aspects: emergence, propagation, and modification. The sweet-potato washing showed these three aspects successfully. First, emergence - it was the monkey nicknamed "Imo" who first started doing this behavior. It seemed to represent her original innovation. No monkeys in the preceding years had performed this behavior. The second is propagation; the new behavior spread through the Koshima troop along two different channels, kinship relations and playmates. Imo's mother and siblings followed her in washing potatoes. The young monkeys a year older than Imo and a year younger than Imo also adopted her practice.

Not many people recognize the third important aspect, modification. The sweet-potato washing was first done in the fresh water of a small stream. Then, during the course of transmission through generations, the monkeys started to carry the potatoes to the sea. They not only washed the potatoes but also immersed them in the sea. Their motivation might have been to get the salty taste. Thus, the sweet-potato washing became the first strong evidence of cultural behavior in nonhuman animals.

The fact was already well known among primatologists. However, it later became very famous among the general public in the West through the popular book written by an American writer Ken Keyes Jr (1921-1995). The book, entitled "The Hundredth Monkey", was published in 1981. The book promoted the political movement to stop nuclear weapons. It misrepresented the original observations on Koshima Islet, but the description was probably intended as a sort of parable.

The story, as reported in his book, is as follows. A new habit of washing sweet-potato originated in a troop of monkeys living on Koshima Islet, Japan. It then spread throughout this particular troop. The number of monkeys washing potatoes gradually increased to 99 individuals. Then, when the critical number of 100 was reached, the behavior instantaneously spread, across the water, to other monkeys living in different places, who now also started washing potatoes: the hundredth monkey effect.

It is a metaphor. However, readers did not always appreciate this and many took his story literally. The book became a worldwide best-seller. In my understanding, he postulates that there must be common features shared by all human beings. Therefore, it is not necessary for there to be an explicit movement against nuclear issues. It is important to think deeply about the nature of these problems. It is important to share your thoughts on the matter with your close friends. This thought will then spread gradually into the community. Then, suddenly, when it reaches a critical number, the nuclear problem will be stopped. The metaphor is based on the idea of group-consciousness or universal thinking among humans. He likely also wanted to spread optimism for the success of the cause.

The idea of the $100^{\text {th }}$ monkey phenomenon, in other words the "hundredth monkey effect", was not originally Keyes's, but came from Lyall Watson (1939-2008). He wrote a book titled "Lifetide" in 1979. Watson was a student of Desmond Morris (1928-), the author of "The Naked Ape". Watson was a zoologist and was also attracted to religions such as Ohmoto-kyo, a Japanese Shinto sect. The concept, invented by him in the 1979 book, became very popular. The tale was taken as fact. Based on peoples' wishful thinking and imagination, the story thus went far beyond the factual reality of observations of the monkey troop on Kohshima Islet.

I have assumed the role of General Director of the Japan Monkey Centre (JMC) and the Editor-in-chief of the journal Primates. This is an unpaid, volunteer role while I am a Professor of Kyoto University Primate Research Institute. Few people are aware that there is another tradition of sweet-potato washing at the JMC.

The JMC monkeys are famous as fire lovers. They do not appear to be as afraid of fire as most animals initially are. This troop was brought from Yakushima island in 1956 when the JMC was first established. On September 26 1959, a super typhoon hit the area of Nagoya that destroyed the houses and caused 5238 deaths. The disaster brought the JMC much wooden material and also fallen trees and branches. The caretaker started making fires in the winter of that same year.

During winter, it became the caretaker's habit to build a fire to keep warm. The monkeys loved to stay near to the fire. Then, the caretakers started giving baked sweet potatoes to the monkey troop. The monkeys eagerly ate the very hot sweet potatoes given to them. Then, much later, on April 26 1997, the troop was relocated to a new habitat at the JMC in which a small pond was provided. Then the alpha male monkey, named Surume, started sweet-potato washing in the water in December 1997. This was apparently to cool the hot sweet potato given to him, in the water. The habit gradually spread into the monkey community. By 2007, almost all members had learned the behavior. 
Although the behavior originated with the hot sweet potatoes, the monkeys down the generations started washing fresh sweet potatoes, too. Then they washed apples and other food in the water. Again, you can see the three important aspects of culture: emergence, propagation, and modification in the case report of JMC monkeys. It is easy for visitors to see the washing behavior of monkeys in the JMC zoo. The JMC has a multilingual web site; please visit it to get more information: http://www.japanmonkey centre.org/.

\section{Reference}

Kawai M (1965) Newly acquired pre-cultural behavior of the natural troop of Japanese monkeys on Koshima Islet. Primates 6:1-30 